\title{
Occupational Exposure to Blood and Body Fluids among Health-Care Workers in Serbia
}

\author{
Ljiljana Markovic-Denic $^{a} \quad$ Natasa Maksimovic $^{a} \quad$ Vuk Marusic $^{a} \quad J_{\text {Jelena Vucicevic }}^{b}$ \\ Irena Ostric ${ }^{\mathrm{a}}$ Dusan Djuric ${ }^{\mathrm{c}}$ \\ anstitute of Epidemiology, Faculty of Medicine, University of Belgrade, Belgrade, ${ }^{b}$ Health Center, Mladenovac, and \\ 'Faculty of Medical Sciences, University of Kragujevac, Kragujevac, Republic of Serbia
}

\section{Key Words}

Needlestick injuries · Health-care workers · Body fluids .

Occupational exposure $\cdot$ Underreporting

\begin{abstract}
Objectives: The aim of this study was to examine the epidemiology of occupational accidents and self-reported attitude of health-care workers (HCWs) in Serbia. Subjects and Methods: A cross-sectional study was conducted among HCWs in selected departments of five tertiary care hospitals and in one secondary care hospital in February 2012. A previously developed self-administered questionnaire was provided to HCWs who had direct daily contact with patients. $X^{2}$ test and Student's $t$ test were used for statistical analysis of the data. $\boldsymbol{R e}$ sults: Of the 1,441 potential participants, $983(68.2 \%) \mathrm{com}$ pleted the questionnaire: 655 (66.7\%) were nurses/medical technicians, 243 (24.7\%) were physicians and $85(8.6 \%)$ were other personnel. Of the 983 participants, 291 (29.6\%) HCWs had had at least one accident during the previous year and $106(40.2 \%)$ of them reported it to the responsible person. The highest prevalence $(68.6 \%)$ of accidents was among nurses/ technicians $(p=0.001)$. Accidents occurred more often in large clinical centers $(81.1 \% ; p<0.001)$ and in the clinical ward, intensive care unit and operating theater $(p=0.003)$
\end{abstract}

than in other departments. Seventy-six (13.1\%) nurses/medical technicians had an accident during needle recapping ( $p<$ 0.001). Of all the HCWs, 550 (55.9\%) were fully vaccinated, including significantly more doctors $(154,63.4 \%)$ than participants from other job categories $(p<0.001)$. Conclusion: There was a relatively high rate of accidents among HCWs in our hospitals, most commonly amongst nurses and staff working in clinical wards, intensive care units and operating theaters. The most common types of accidents were needlestick injuries and accidents due to improper handling of contaminated sharp devices or occuring while cleaning instruments or by coming into contact with blood through damaged skin or through the conjunctiva/mucous membranes.

ㄷ) 2014 S. Karger AG, Basel

\section{Introduction}

Health-care workers (HCWs) are exposed to blood and body fluids due to occupational accidents which can result from percutaneous injury (needlestick or other sharps injury), mucocutaneous injury (splashes of blood or other body fluids into the eyes, nose or mouth) or blood contact with damaged skin [1]. Consequently, HCWs are at risk of infection from blood-borne viruses,

\begin{tabular}{ll}
\hline KARGER 125:s & $\begin{array}{l}\text { () 2014 S. Karger AG, Basel } \\
1011-7571 / 14 / 0241-0036 \$ 39.50 / 0 \quad \text { Karger }\end{array}$ \\
$\begin{array}{l}\text { E-Mail karger@karger.com } \\
\text { www.karger.com/mpp }\end{array}$ & $\begin{array}{l}\text { This is an Open Access article licensed under the terms of the } \\
\text { Creative Commons Attribution-NonCommercial 3.0 Un- } \\
\text { ported license (CC BY-NC) (www.karger.com/OA-license), } \\
\text { applicable to the online version of the article only. Distribu- } \\
\text { tion permitted for non-commercial purposes only. }\end{array}$
\end{tabular}

Ljiljana Markovic-Denic

Institute of Epidemiology, Faculty of Medicine, University of Belgrade

Visegradska 26, Postanskipregradak 20

RS-11129 Belgrade 102 (Republic of Serbia)

E-Mail lj.denic@gmail.com 
including human immunodeficiency virus (HIV), hepatitis B (HBV) and hepatitis C virus. These blood-borne infections have serious consequences, including longterm illness, disability and death $[2,3]$. The risk of accidental contact with blood and body fluids is especially increased in the following situations: while taking blood samples, during intravenous cannulation, intramuscular or subcutaneous injection, recapping of already used needle(s), surgery - especially during wound closure, and during clean up and transportation of waste materials.

Each year, among the 35 million HCWs worldwide, about 3 million are exposed to blood-borne pathogens through a percutaneous route [1]. These injuries result in 15,000 hepatitis $C$ virus infections, $70,000 \mathrm{HBV}$ infections and 500 HIV infections each year [1]. The risk of infection for HCWs from blood-borne pathogens depends on the prevalence of these pathogens among the patient population and the nature and frequency of exposures [1].

The risks of occupational accidents for HCWs and their attitude and practices in high-income [4-6] and middle-income countries [7-10] have been reported. However, the situation for HCWs in southeastern European countries is not well documented [11-13]. Therefore, the aim of this study was to examine the epidemiology of occupational accidents and self-reported attitude of HCWs in Serbia.

\section{Subjects and Methods}

A cross-sectional study was conducted among HCWs in February 2012 at five departments of tertiary care hospitals in Belgrade (the Clinical Center of Serbia, the Emergency Center, the Clinical Hospital Center Zemun, the Clinic for Rehabilitation, and the neonatology department in the Hospital for Children, Lung Disease and Tuberculosis) and at one secondary care interstate hospital (the General Hospital in Sabac). The survey incorporated pulmonary, cardiology, infectious diseases, neonatology, surgery with anesthesiology and physical rehabilitation departments within these hospitals.

Serbia is a country in transition with many financial problems affecting the economy and, consequently, with problems in the health-care sector [14]. After the dissolution of the former Yugoslavia, Serbia was faced with international sanctions, North Atlantic Treaty Organization (NATO) aggression, and political and economic crisis. A decline in productivity, increased unemployment and the unfavorable structure for production and export resulted in a reduction in resources for health care [15]. Although the total expenditure for health care in Serbia is above the European Union average, it allocates a small absolute amount of funds for health care due to a high rate of unemployment, low average salary and small basis for taxation [16]. Health system financing is mainly provided by the Health Insurance Fund. Private funding is supplemented by contributions from a small number of major companies and is based on out-of-pocket payments, primarily for primary care services. However, hospital care is free of charge for all. There is only a small number of private clinics in Serbia. As a consequence of this unfavorable situation, equipment and facilities have not been modernized for many years [17].

The national surveillance system of nosocomial infections was only recently established, safety equipment is relatively rare and a lack of personal protective equipment is very common in Serbian hospitals. However, there is a major effort to increase the knowledge of HCWs and to improve their practices regarding needlestick and sharp injuries. An estimation of the frequency of accidents is the first step in their reduction, as has been shown by other countries $[3,4,8-10,18]$. Therefore, we planned to organize a large survey of occupational accidents, commencing in the main hospitals in the country.

Based on previously published studies $[1-4,7,18]$, a draft version of a self-administered questionnaire was developed. This version was given to $15 \mathrm{HCW}$ s at one tertiary care hospital for pretesting to determine if the questions were understandable, the respondents felt comfortable answering them, the answer choices were compatible with the respondents' experience, all respondents interpreted the questions in the same way and the questions measured what they were intended to do.

The questionnaire was reviewed again, and the study group prepared its final version. This questionnaire was previously used in the pilot study conducted in one specialized hospital [19] which is not included in this study. The questionnaire was distributed to 1,441 HCWs from selected departments of the studied hospitals who had direct daily contact with patients. These included doctors as well as nurses and medical technicians (who have similar education levels in Serbia) and other hospital staff (health assistants and hospital hygienists).

Participation was voluntary and anonymous. Four pretrained interviewers were responsible for distributing the questionnaires. All HCWs at the study departments were asked to complete and return the questionnaire during working hours on the day of the survey. The questionnaires were handed to the HCWs at their workplace during working breaks, with repeated contacts being arranged for absent staff. All HCWs were asked to participate in the study except for those on vacation, those who had a day off or those who were on sick leave during the study period. The questionnaire included 28 closed questions that included demographic characteristics (age, gender, occupation, position and length of employment), the number of accidents occurring during working hours, the place and the circumstances of these accidents as well as the measures taken after an accident and questions on vaccination for HBV.

\section{Statistical Analysis}

Descriptive and analytical statistics ( $\chi^{2}$ test and Student's t test) were used in the data processing. A $p$ value $<0.05$ was considered statistically significant. Data from the questionnaires were coded and entered into a database, and analysis was done using the SPSS v.17.0 software package for Microsoft Windows. The lifetime prevalence of accidents and the prevalence in the year prior to the study (the prevalence of accidents in the previous year) were calculated. The prevalence in the previous year was calculated as the percentage of workers who had reported at least one accident during the 12 months preceding the study. Explanatory variables included respondents' gender, occupation (doctor, nurse/medical technician, 
and other), the type of ward, hospital type, and work shift. The length of service at the present ward was presented as a continuous variable. A series of binary variables indicating 1 were used for 'needlestick injury before using needle', 'needle recapping', 'handling of contaminated sharp devices', 'contact with blood through damaged skin/conjunctiva/mucous membranes' and 'during cleaning instruments'.

\section{Results}

Of the 1,441 questionnaires distributed, 983 were returned, thereby giving a response rate of $68.2 \%$. The demographic characteristics of the respondents are shown in table 1. Of the 983 participants, 655 (66.7\%) were nurses or medical technicians, 243 were physicians $(24.7 \%)$ and 85 were other personnel (health assistants and hospital hygienists, $8.6 \%$ ). There were more women (736, $74.9 \%)$ than men $(247,25.1 \%)$. The median age of the respondents was 37.0 years (range 20-65), and the median duration of employment was 13.0 years (range $0.5-$ $40)$. Only $10(1.1 \%)$ of the respondents had worked for less than 1 year. The majority of HCWs $(316,32.1 \%)$ worked on clinical wards, followed by surgical intensive care units $(242,24.6 \%)$ and operating theaters (160, $16.3 \%)$. The highest percentage $(n=490,50.5 \%)$ of respondents stated that they worked all shifts, whereas 372 $(38.3 \%)$ reported that they worked only morning shifts.

Of the 983 respondents, 555 HCWs had had at least one accident at some point in their career in a health-care facility. Therefore, the lifetime prevalence was $56.5 \%$ (95\% CI 53.3-59.5). Among these 555 HCWs, 264 had had an accident in the past year, thus the prevalence in the previous year was $26.9 \%$ (95\% CI 24.2-29.7). The prevalence of accidents in the previous year was highest among nurses/technicians $(181,68.6 \%)$, followed by doctors $(74$, $28.0 \%)$ and other HCWs $(9,3.4 \%$; $\mathrm{p}=0.001)$.

The distribution of accidents in the previous year by hospital type (clinical center, clinical hospital center and general hospital) and by the department types are given in table 2. Accidents occurred more frequently in large clinical centers $(\mathrm{p}<0.001)$, and in clinical wards, intensive care units and operating theaters $(\mathrm{p}=0.003)$.

An overview of the nature of the activities by job category during which the occupational exposures occurred is listed in table 3. Nurses/medical technicians had a statistically higher number of accidents during needle recapping ( $\mathrm{p}<0.001)$, handling of contaminated sharp devices $(\mathrm{p}=0.01)$ and cleaning of instruments $(\mathrm{p}=0.011)$, and more often had contact with blood through damaged skin $(\mathrm{p}=0.004)$. Doctors had more frequent contact with
Table 1. Demographic characteristics of the study population

$\begin{array}{lc}\text { Gender } & \\ \text { Male } & 247(25.1) \\ \text { Female } & 736(74.9) \\ \text { Age, years } & 38.4 \pm 10.5 \\ \text { Duration of employment, years } & 14.4 \pm 10.2 \\ \text { Occupation } & \\ \text { Doctor } & 243(24.7) \\ \text { Nurse/medical technician } & 655(66.7) \\ \text { Other } & 85(8.6) \\ \text { Ward } & \\ \text { Surgical admission unit } & 82(8.3) \\ \text { Outpatient department } & 44(4.5) \\ \text { Clinical ward } & 316(32.1) \\ \text { Operating theater } & 160(16.3) \\ \text { Surgical intensive care unit } & 242(24.6) \\ \text { Laboratory } & 27(2.7) \\ \text { Other } & 112(11.4) \\ \text { Working shift } & \\ \text { Morning shift } & 372(38.3) \\ \text { Only day shift } & 91(9.3) \\ \text { Only night shift } & 18(1.9) \\ \text { All (day work) } & 490(50.5)\end{array}$

Values represent $\mathrm{n}(\%)$ or mean $\pm \mathrm{SD}$.

Table 2. Accident distribution by hospital and unit type

\begin{tabular}{lccc}
\hline Characteristics & $\begin{array}{l}\text { No } \\
\text { accidents }\end{array}$ & $\begin{array}{l}\geq 1 \\
\text { accident }\end{array}$ & $\begin{array}{l}\mathrm{p} \\
\text { value }\end{array}$ \\
\hline $\begin{array}{l}\text { Hospital type } \\
\text { Clinical center }\end{array}$ & $412(57.3)$ & $214(81.1)$ & $<0.001$ \\
Clinical hospital center & $127(17.7)$ & $30(11.4)$ & \\
General hospital & $180(25.0)$ & $20(7.6)$ & \\
Unit type & & & 0.003 \\
Surgical admission ward & $60(8.3)$ & $22(8.3)$ & \\
Outpatient department & $36(5.0)$ & $8(3.0)$ & \\
Clinical ward & $228(31.7)$ & $88(33.3)$ & \\
Operating theater & $102(14.2)$ & $58(22.2)$ & \\
Surgical intensive care unit & $175(24.3)$ & $67(25.4)$ & \\
Laboratory & $21(2.9)$ & $6(2.3)$ & \\
Others & $97(13.5)$ & $15(5.7)$ & \\
\end{tabular}

Values represent n (\%) of respondents.

blood through the conjunctiva/mucous membranes $(\mathrm{p}=$ 0.002).

Accidents were more frequent in clinical centers (142, 81.1\%) than in clinical hospital centers and hospitals (d.f. $=2, p=0.001$ ). Staff in clinical centers had a statistically higher number of accidents before using a needle 
Table 3. Selected accident sources and circumstances by job category

\begin{tabular}{|c|c|c|c|c|}
\hline Needlestick injury & $118(67.4)$ & $53(30.3)$ & $4(2.3)$ & 0.859 \\
\hline Before using needle & $61(67.8)$ & $27(30.0)$ & $2(2.2)$ & 0.524 \\
\hline Needle recapping & $76(86.4)$ & $12(13.6)$ & $0(0.0)$ & $<0.001$ \\
\hline Handling of contaminated sharp devices & $85(63.0)$ & $48(35.6)$ & $2(1.5)$ & 0.01 \\
\hline Contact with blood through conjunctiva/mucous membranes & $28(70.0)$ & $36(92.3)$ & $1(25.0)$ & 0.002 \\
\hline Cleaning instruments after surgical procedure & $24(19.5)$ & $1(2.3)$ & $0(0.0)$ & 0.011 \\
\hline
\end{tabular}

Values represent $\mathrm{n}(\%)$.

Table 4. HBV vaccination status according to occupation and type of hospital

\begin{tabular}{|c|c|c|c|}
\hline \multirow[t]{2}{*}{ Variable } & \multicolumn{2}{|c|}{$\mathrm{HBV}$ vaccination status } & \multirow{2}{*}{$\begin{array}{l}\mathrm{p} \\
\text { value }\end{array}$} \\
\hline & $\begin{array}{l}\text { nonvaccinated }^{1} \\
(\mathrm{n}=433)\end{array}$ & $\begin{array}{l}\text { fully } \\
\text { vaccinated } \\
(\mathrm{n}=550)\end{array}$ & \\
\hline \multicolumn{3}{|l|}{ Occupation } & 0.025 \\
\hline Doctor & $89(36.6)$ & $154(63.4)$ & \\
\hline Nurse/technician & $306(46.7)$ & $349(53.3)$ & \\
\hline Other & $38(44.7)$ & $47(8.5)$ & \\
\hline \multicolumn{3}{|l|}{ Hospital type } & $<0.001$ \\
\hline Clinical center & $331(52.9)$ & $295(47.1)$ & \\
\hline \multicolumn{4}{|l|}{ Clinical hospital } \\
\hline center & $73(46.5)$ & $84(53.5)$ & \\
\hline General hospital & $29(14.5)$ & $171(85.5)$ & \\
\hline
\end{tabular}

Values represent $\mathrm{n}(\%)$ of respondents.

${ }^{1}$ Nonvacinated or vaccinated with only one or two doses.

$(79,87.8 \% ; \mathrm{p}<0.001)$, during handling of contaminated sharp devices $(51,78.5 \% ; \mathrm{p}=0.001)$, contact with blood through damaged skin $(79,84.9 \% ; \mathrm{p}=0.001)$ and conjunctiva/mucous membranes $(50,74.9 \% ; \mathrm{p}=0.001)$. However, there was no difference among HCWs at different levels of health facilities in injuries received during needle recapping and cleaning of instruments $(\mathrm{p}>0.05)$.

Out of 264 participants, 106 (40.2\%) had reported an accident to the responsible authority in the past year. Accidents were significantly more often reported by health assistants and hospital hygienists $(5,55.5 \%)$, followed by nurses/medical technicians $(81,44.7 \%)$, than by doctors $(20,31.5 \% ; \mathrm{p}=0.02)$.

Occupational Exposure of HCWs
Levels of immunization against HBV are shown in table 4 . Of the 983 participants, 550 (56\%) of all HCWs were fully immunized, with a significantly greater proportion of these being doctors $(154,63.4 \%)$ than HCWs coming from other job categories $(\mathrm{p}<0.001)$. Staff working in the general hospital were fully vaccinated to a significantly higher percentage $(171,58.5 \%)$ than in the clinical hospital centers $(84,53.5 \%)$ and clinical centers $(295,47.1 \%$; $\mathrm{p}<0.001)$.

\section{Discussion}

The $27 \%$ prevalence rate of accidents occurring within the previous year is similar to that in less developed countries such as Romania (35\%) [11], Ethiopia (30.9\%) [20], and some hospitals in Mongolia (29\%) [9] and the Dominican Republic (22.3\%) [21]. The rates in developing countries $[7-11,20,21]$ are always generally higher than rates in developed countries (from 1.8 to 5.8\%) [4-6] due to insufficient staff and long working hours, lack of experience and educational programs, and lack of safety equipment and suboptimal standard precautions compliance $[8,9,20]$. In our study, less than half of HCWs reported accidents to the responsible authorities within their institutions. However, the underreporting of injuries is still an important problem even in developed counties. For example, the mean rates of underreporting of sharps injuries vary from 22 to $75 \%$ [22, 23], which can delay proper medical evaluation and treatment. According to the results of a German study [24], the annual prevalence of all occupational exposure to body fluids was approximately $32 \%$, with a mean rate of underreporting of approximately $45 \%$, when data from self-administrated 
questionnaires were compared with data from the occupational medicine service. The most likely reasons why HCWs underreport an accident include the incident being forgotten, the risk being underestimated, a reluctance to admit a lack of knowledge surrounding the handling of certain instruments, fear of positive serological test results, workload pressure and time constraints [22, 23].

Our results revealed significantly more accidents in clinical wards (33.3\%), intensive care units (25.4\%) and operating theaters $(22.2 \%)$ than in other departments (5.7\%). A probable explanation for this is that HCWs have an increased risk of exposure to blood and body fluids in such locations as the operating theaters, delivery and emergency rooms and laboratories. Cleaners, waste collectors and others whose duties involve handling blood-contaminated items are also at risk. In a Turkish study [25] accidents were also frequent in the respective areas of operating theaters $(56 \%)$, intensive care units (50\%) and laboratories (23\%). The results of that study are much more accurate compared to ours due to dermatological examinations for the presence of abrasions on the HCWs hands that were carried out on the day of the questionnaire. An occupational exposure to blood or other body fluids during accidents is one of the most serious threats facing HCWs. This exposure can lead to the transmission of pathogens causing an infection with serious implications for their health $[3,14]$.

Needlestick injuries are the most common form of occupational exposure to blood and the most likely to result in infection [23]. Nearly $80 \%$ of all percutaneous sharps injuries were caused by a needlestick, with $56 \%$ attributed to hollow-bore needles. The most common causes of needlestick injury were two-handed recapping and unsafe collection and disposal of sharp-object waste $[1,15]$.

According to our results, nurses had a higher number of accidents during needle recapping and handling of contaminated sharp devices. They had significantly more frequent contact with blood through damaged skin, while doctors had more contact with blood through the conjunctiva or mucous membranes. This can be explained by overcrowding in Serbian hospitals, the lack of safety-engineered devices (needles, syringes) that allow better protection for HCWs, or the neglect of occupational risks. Hence, there is an urgent need for establishing a national surveillance system of needlestick injuries and accidents in health facilities. Moreover, improving knowledge about risk perception and reporting accidents would allow prompt application of preventive measures in our hospitals. It is well known that effective prevention of needlestick injuries requires a comprehensive approach combining various strategies. Use of safe needle devices and adoption of safe working practices are essential components in the prevention of occupational accidents [26, 27].

In our study, about $56 \%$ of HCWs were fully immunized. An occupational risk of HBV can be decreased by simple and relatively cheap measures such as vaccinations. Even if $\mathrm{HBV}$ is $95 \%$ preventable with immunization, less than $20 \%$ of the HCWs in some regions of the world have received all three vaccine doses required for immunity $[1,28]$.

\section{Conclusion}

There was a high rate of accidents among HCWs in our hospitals, most commonly among nurses and staff working in clinical wards, intensive care units and operating theaters. The most common accidents were needlestick injuries and those resulting from an improper handling of contaminated sharp devices, those sustained while cleaning instruments, and contact with blood through damaged skin or through the conjunctiva/mucous membranes.

\section{Acknowledgements}

This study was conducted as part of project 175046 funded by the Ministry of Education, Science and Technological Development, Republic of Serbia, 2011-2014.

References

1 World Health Organization: Health care worker safety: AIDE-MEMOIRE for a strategy to protect health workers from infection with bloodborne viruses. 2013. http://www. who.int/injection_safety/toolbox/en/AM_ HCW_Safety_EN.pdf (accessed August 16, 2013).

2 Rapiti E, Prüss-Üstün A, Hutin Y: Sharps injuries: assessing the burden of disease from sharps injuries to health-care workers at national and local levels. WHO Environmental Burden of Disease Series, No. 11. Geneva, World Health Organization, 2005.

-3 Prüss-Ustün A, Rapiti E, Hutin Y: Estimation of the global burden of disease attributable to contaminated sharps injuries among healthcare workers. Am J Ind Med 2005;48:482.

4 Smith DR, Mihashi M, Adachi Y, et al: Epidemiology of needlestick and sharps injuries among nurses in a Japanese teaching hospital. J Hosp Infect 2006;64:44-49. DOI: $10.1159 / 000368234$
Markovic-Denic et al. 
$>5$ Tosini W, Ciotti C, Goyer F, et al: Needlestick injury rates according to different types of safety-engineered devices: results of a French multicenter study. Infect Control Hosp Epidemiol 2010;31:402-407.

6 Saia M, Hofmann F, Sharman J, et al: Needlestick injuries: incidence and cost in the United States, United Kingdom, Germany, France, Italy and Spain. Biomed Int 2010;1:41-49.

7 Zafar A, Aslam N, Nasir N, et al: Knowledge, attitudes and practices of healthcare workers regarding needlestick injuries at a tertiary care hospital in Pakistan. J Pak Med Assoc 2008;58:57-60.

$>8$ Serinken M, Karcioglu O, Kutlu SS, et al: A survey of needlesticks and sharp instrument injuries in emergency health care in Turkey. J Emerg Nurs 2009;35:205-210.

-9 Kakizaki M, Ikeda N, Ali M, et al: Needlestick and sharps injuries among healthcare workers at public tertiary hospitals in an urban community in Mongolia. BMC Res Notes 2011:4:184.

10 Shiva F, Sanaei A, Shamshiri AR, et al: Survey of needle-stick injuries in paediatric health personnel of 5 university hospitals in Tehran. J Pak Med Assoc 2011;61:127-131.

11 Dentinger C, Pasat L, Popa M, et al: Injection practices in Romania: progress and challenges. Infect Control Hosp Epidemiol 2004;25: 30-35.

12 Falagas ME, Karydis I, Kostogiannou I: Percutaneous exposure incidents of the health care personnel in a newly founded tertiary hospital: a prospective study. PLoS One 2007; 2:e194.
13 Jankovic S, Bojanic J, Jovic-Vranes A, et al: Knowledge, attitudes and practices towards blood-borne pathogens in healthcare workers in Banja Luka, Bosnia and Herzegovina. Cent Eur J Med 2009;4:409-414.

14 Vlahovic Z, Radojkovic D: Healthcare in Serbia in transition period. EPMA J 2010;1:601606.

15 Bozic Miljkovic I: Serbian economy in transitional, European and world economic crisis. Eur Sci J 2013;9:38-55.

16 Stošić S, Karanović N: Health care economics in Serbia: current problems and changes. Vojnosanit Pregl 2014, Epub ahead of print. http://www.doiserbia.nb.rs/img/doi/0042$8450 / 2014 \% 20$ OnLine - First / 0042 84501400002 S.pdf.

17 Gavrilovic A, Trmcic S: Health insurance system in Serbia - quality, reform, financial sustainability. MEST J 2013;1:114-126.

18 Centers for Disease Control and Prevention: Updated US Public Health Service guidelines for the management of occupational exposures to HBV, HCV, and HIV and recommendations for postexposure prophylaxis. MMWR Recomm Rep 2001;50(RR11):1-52.

19 Markovic-Denic LN, Mihajlovic B, CemerlicAdjic N, et al: The effect of training programs to reduce needlestick injuries. BMC Proc 2011;5(suppl 6):P217.

20 Tadesse M, Tadesse T: Epidemiology of needlestick injuries among health-care workers in Awassa City, Southern Ethiopia. Trop Doct 2010;40:111-113.

21 Moro PL, Moore A, Balcacer P, et al: Epidemiology of needlesticks and other sharps injuries and injection safety practices in the Dominican Republic. Am J Infect Control 2007; 35:552-559.
22 Doebbeling BN, Vaughn TE, McCoy KD, et al: Percutaneous injury, blood exposure, and adherence to standard precautions: are hospital-based health care providers still at risk? Clin Infect Dis 2003;37:1006-1013.

23 Elmiyeh B, Whitaker IS, James MJ, et al: Needle-stick injuries in the National Health Service: a culture of silence. J R Soc Med 2004; 97:326-327.

24 Schmid K, Schwager C, Drexler H: Needlestick injuries and other occupational exposures to body fluids amongst employees and medical students of a German university: incidence and follow-up. J Hosp Infect 2007;65: 124-130.

25 Sencan I, Sahin I, Yildirim M, et al: Unrecognized abrasions and occupational exposures to blood-borne pathogens among health care workers in Turkey. Occup Med 2004;54:202206

26 Karim J, Al-Saraji M, Al-Mousawi F, et al: Knowledge and self-reported practice of universal precautions among Kuwait University medical students in their clinical years. Med Princ Pract 2012;21:328-333.

27 Trim JC, Elliott TSJ: A review of sharps injuries and preventative strategies. J Hosp Infect 2003;53:237-242.

28 Azodo CC, Ehigiator O, Ojo MA: Occupational risks and hepatitis $\mathrm{B}$ vaccination status of dental auxiliaries in Nigeria. Med Princ Pract 2010;19:364-366. 